\title{
Surface Microhardness, Flexural Strength, and Clasp Retention and Deformation of Acetal vs Poly-ether-ether Ketone after Combined Thermal Cycling and pH Aging
}

\author{
Salma Mahmoudd Fathy ${ }^{1}$, Radwa Mohsen Kamal Emera², Reham Mohamed Abdallah ${ }^{3}$
}

\begin{abstract}
Aim: To evaluate the effect of combined thermocycling and artificial saliva $\mathrm{pH}$ on flexural strength, surface microhardness, as well as clasp retention and deformation of two different thermoplastic polymers.

Materials and methods: Three groups were created, heat-cured polymethyl methacrylate, acetal, and poly-ether-ether ketone (PEEK) resins. Specimens were wrapped in plastic bags containing artificial saliva with three $\mathrm{pH}$ values (acidic 5.8, neutral 7.2, and alkaline 8.3). Two Aker clasps materials (acetal and PEEK), for premolar and molar, were stored in neutral salivary pH. Specimens were subjected to 2,000 thermocycles $\left(5-55^{\circ} \mathrm{C}\right)$. Surface microhardness, flexural strength, and clasp retention and deformation were evaluated before and after aging. Data were analyzed by ANOVA, Tukey's test, Student's $t$-test, and paired $t$-tests $(p<0.05)$.

Results: Thermal cycling at acidic and alkaline $\mathrm{pH}$ significantly decreased flexural strength and surface microhardness of acetal. It had no significant effect on PEEK properties. Poly-ether-ether ketone showed statistically significant higher mechanical properties in all groups. Acetal clasps exhibited a statistically significant deformation and a corresponding decrease in retention after thermocycling at neutral pH.

Conclusion: Mechanical properties of acetal, as well as its clasp retention and deformation, significantly decreased after combining thermal and $\mathrm{pH}$ aging and thermal cycling in neutral $\mathrm{pH}$, respectively. Meanwhile, PEEK clasps were not significantly affected.

Clinical significance: Different intraoral variables may significantly affect mechanical performance, retention, and deformation of TMs used for denture base and clasp construction. Some of these TMs may behave better than the other types with recommended improvement of the design like increasing clasp cross-section area.

Keywords: Artificial saliva pH, Clasp retention, Deformation, Thermal cycling, Thermoplastic resins.

The Journal of Contemporary Dental Practice (2021): 10.5005/jp-journals-10024-2937
\end{abstract}

\section{INTRODUCTION}

The harsh intraoral environment affects the performance and longevity of denture prostheses. They are usually under variations in temperatures because of the ingestion of hot and cold liquids. ${ }^{1,2}$ Moreover, they are subjected to fluctuating $\mathrm{pH}$ of saliva that could be either acidic, on the intake of orange juice, candy, or smoking, or alkaline, on eating amaranth or oversecreting pancreatic juice. ${ }^{3}$ Furthermore, wet oral environment as well as occlusal forces and habits ${ }^{4}$ could accelerate the degradation of the denture polymer. ${ }^{5}$

Although in vitro studies do not simulate precisely the intraoral environment, dynamic simulations are better candidates for predating the materials' clinical performance. ${ }^{6}$ One of the systems that produce dynamic stresses is thermal cycling in a wet environment. It is widely used and accepted in the dental literature. ${ }^{7}$

Currently used thermoplastic resins (TPRs) in dentistry are composite materials or copolymers that exhibit flexible performance with no residual monomer or allergic additives. ${ }^{8}$ Acetal is a polyoxymethylene (POM) TM first proposed as an unbreakable resin in 1971. It is flexible, light in weight, and indicated for removable dentures constructions and known as dental "D." It has high mechanical properties like surface hardness and wears resistance with high working temperature when it is in copolymer form. ${ }^{8,9}$ Consequently, it is indicated for reintroduced tooth-colored clasps fabrication. However, POM does not have high thermal and chemical stability. ${ }^{8}$ Despite of that, most researches ${ }^{10-13}$ studied the effect of mechanical fatigue cycling on mechanical properties of the acetal clasps and other TMs, neglecting the effect of thermal
${ }^{1}$ Dental Biomaterials Department, Faculty of Dentistry, Zagazig University, Zagazig, Egypt

${ }^{2}$ Prosthodontics Department, Faculty of Dentistry, Mansoura University, Mansoura, Egypt

${ }^{3}$ Dental Biomaterials Department, Faculty of Dentistry, Mansoura and Horus Universities, Mansoura and New Damietta, Egypt

Corresponding Author: Salma Mahmoudd Fathy, Dental Biomaterials Department, Faculty of Dentistry, Zagazig University, Zagazig, Egypt, Phone: +201000153552, e-mail: Salmafathy_dent@edu.eg

How to cite this article: Fathy SM, Emera RMK, Abdallah RM, et al. Surface Microhardness, Flexural Strength, and Clasp Retention and Deformation of Acetal vs Poly-ether-ether Ketone after Combined Thermal Cycling and pH Aging. J Contemp Dent Pract 2021;22(2): 140-145.

Source of support: Nil

Conflict of interest: None

and chemical stresses on such mechanical properties. Poly ether-ether-ketone (PEEK) is another famous high-performance thermoplastic aromatic polymer. It is a two-phase, semicrystalline polymer with a degree of crystallinity between 30 and $35 \%$, depending on the manufacturing process. ${ }^{14}$ It is characterized by high mechanical properties and excellent biocompatibility. It is regarded as a suitable material for a removable denture framework and its components, including an esthetic clasp. ${ }^{15}$ Previous studies reported a reduction in mechanical properties and prominent 
discoloration of various types of dental TMs after aging in artificial saliva, alcohol, distilled water, coffee, and wine. ${ }^{16,17}$ Studying the impact of various oral conditions on all denture base materials' performance and mechanical properties is of high importance. Accordingly, the objective of the current study was to evaluate the effect of complex variable environment of thermocycling dynamic stresses and different $\mathrm{pH}$ values within the wet environment on the mechanical properties and clasp retention and deformation of acetal and PEEK TMs.

\section{Materials and Methods}

The current primary research was done through the following steps. A total number of 92 rectangular specimens $(65 \mathrm{~mm} \times 10$ $\mathrm{mm} \times 2.5 \mathrm{~mm}$ ) were prepared for flexural strength testing. A total number of 92 disk-shaped specimens $(10 \mathrm{~mm}$ in diameter and 1 $\mathrm{mm}$ in thickness) were used for surface microhardness testing. Both specimens' shapes were constructed from three denture base resins: heat-cured polymethyl methacrylate (PMMA) acrylic denture base (Vertex-Acrylic resin), acetal TMs (Bioacetal, Roko Dental Systems), and modified PEEK (BioHPP, Bredent GmbH). Three groups were created, for each test, according to the type of material used. Forty Acker clasps were prepared for maxillary molars (group I) and premolars (group II) (20 clasps for each tooth type). They were fabricated from both TMs: acetal (subgroup A) and PEEK (subgroup B). All in all, 20 clasps for each tested material were used.

\section{Specimens Preparation}

For rectangular and disc-shaped specimens, metal bars and discs with the corresponding dimensions were applied to create the mold cavity space within the stone-filled flask. For PMMA heatcured acrylic resin, a compression molding technique was used. For acetal and PEEK, prefabricated sprues were made by modeling wax into a special flask designed for the injection-molding technique. Dewaxing followed to create sprue channels, before applying a thin coat of a separating agent (acrylic-plaster separator, Alphabond Dental) to the model. Dryness is ensured before processing further. According to the manufacturer's instruction, a cartridge of suitable size was selected and placed in an electric cartridge furnace for softening of acetal and PEEK resin at $250^{\circ} \mathrm{C}$ for $15-20$ minutes and at $400^{\circ} \mathrm{C}$ for 20 minutes, respectively. The molten resins were then injected into the mold cavity. This was performed using a digital molding machine (Multipress-digital molding machine-Roko). Finishing was performed to remove resin excess from prepared specimens using finishing stone wheel and burs, then tungsten carbide bur for 2 minutes, and finally sand paper (150) grit. Attention was paid to avoid high heat regeneration during grinding. ${ }^{18}$ Aluminum oxide paste and polishing machine (Universal polishing; Ivoclar Vivadent) were applied in conjunction with a felt-polishing wheel (Shfuinnc, Kyoto) that was attached to an electric motor at a speed of 3,000/rpm.

\section{Preparation of Clasp Specimens}

Two human maxillary first premolars and molars were used for Aker clasp construction. Teeth were intact, noncarious, and unrestored. Each tooth was thoroughly washed under distilled water and scaled using hand sickle scalar (Prima-Dent International) to remove any soft tissue or hard remnants. Minor teeth preparations were performed for occlusal rest seat and proximal guiding plane. Afterward, teeth were embedded vertically up to the level of the cement-enamel junction, in identical rectangular acrylic blocks
(Stellon, DeguDent Gmbh). They were produced using custom-made copper molds ( $30 \mathrm{~mm} \times 20 \mathrm{~mm} \times 25 \mathrm{~mm}$ ). Later, 3-D scanning of blocks with the embedded teeth was performed using a 3-D scanner (Swing 3-D dental scanner) to obtain 3-D virtual images (Figs 1A and 1B). The depth of teeth undercuts evaluation; surveying and clasp design were performed using a software designer program (Exocad software, Dental DB 2.2 Valletta, Version 2.2 Engine build 6654) and depth scale. Digital design of a half-round cross-sectional Aker clasp with attached cylindrical pin holder, to serve as an attachment for fixation to the sample jig holders of the testing machine, was created (Figs 1C and 1D). The stereolithography (STL) files of whole clasp designs were exported to a 3-D printer (Phrozen Shuffle: LCD Resin 3D Printer) to fabricate a 3-D printed resin pattern of each clasp (Fig. 1E). Resin patterns were invested for the subsequent injection molding process for both types of tested TMs. The finished acetal and PEEK clasps (Figs $1 \mathrm{~F}$ and $1 \mathrm{G}$ ) were used for the evaluation of deformation and retention force, before and after aging.

\section{Preparation of Different pH Artificial Saliva Solutions and Thermocycling}

Three artificial saliva solutions with different $\mathrm{pHs}$ (acidic 5.8, neutral 7.2, and alkaline 8.3 ) were prepared. The solutions had the following additives as $\mathrm{g} / \mathrm{L}\left(\mathrm{NaCl} 0.70, \mathrm{Na}_{2} \mathrm{PO}_{4} 0.26, \mathrm{KSCN} 0.33\right.$, $\mathrm{KH}_{2} \mathrm{PO}_{4}$ 0.20). Specimens were divided into three groups according to the $\mathrm{pH}$ values of the tested artificial saliva. Each material group, of both rectangular and disc-shaped specimens, was stored in a transparent, tightly sealed low-density polyethylene (LDPE) plastic bag (Shenzen Packing Co., Ltd) containing $100 \mathrm{~mL}$ of each artificial salivary $\mathrm{pH}$ value and 10 specimens of each material type, five rectangular and five disc-shaped. For Aker clasps, each 10-clasp models were stored in $100 \mathrm{~mL}$ of the prepared artificial saliva with a neutral $\mathrm{pH}$ value of 7.2. Plastic bags, with all specimen types and salivary $\mathrm{pH}$, were subjected to thermocycling in hot water $\left(55^{\circ} \mathrm{C}\right)$ and cold $\left(5^{\circ} \mathrm{C}\right)$ baths for 2,000 cycles with a dwell time of 3 minutes. We increased the dwell time than that of the previous reports ${ }^{19,20}$ to allow temperature transfer through the plastic bag and heat convection between water and artificial saliva. The artificial saliva solutions and plastic bags were renewed every day.

\section{Mechanical Testing}

For flexural strength testing, a three-point bending test was utilized. Specimens were mounted on two parallel stainless steel rods with span length $50 \mathrm{~mm}$. They were statically compression loaded at their center with a crosshead speed of $1 \mathrm{~mm} /$ minute until fracture or maximum flexion using a Universal Testing Machine (Model 3345; Instron Industrial Products, Norwood) with a load cell of $5 \mathrm{kN}$ and data were recorded using computer software (Instron Bluehill Lite Software). The fracture force, measured in Newtons (N), is the force at which failure or instability is imminent. The fracture strength (FS) was calculated $(\mathrm{MPa})$ using the following formula:

$$
\mathrm{FS}(\mathrm{o})=3 F(L) / 2 w h^{2}
$$

where $F$ is the maximum load applied to the specimen in Newton, $L$ is span, $w$ is the width of the specimen, and $h$ is the height. ${ }^{21}$

Vickers hardness numbers (VHNs) for the tested specimens were obtained using a Vickers microhardness tester (HMV Microhardness Tester, Shimadz). A load of $50 \mathrm{~g}$ was applied for a dwell time of 10 seconds by the diamond indenter. Five indentation readings were performed, and the average for them was calculated for each specimen. 


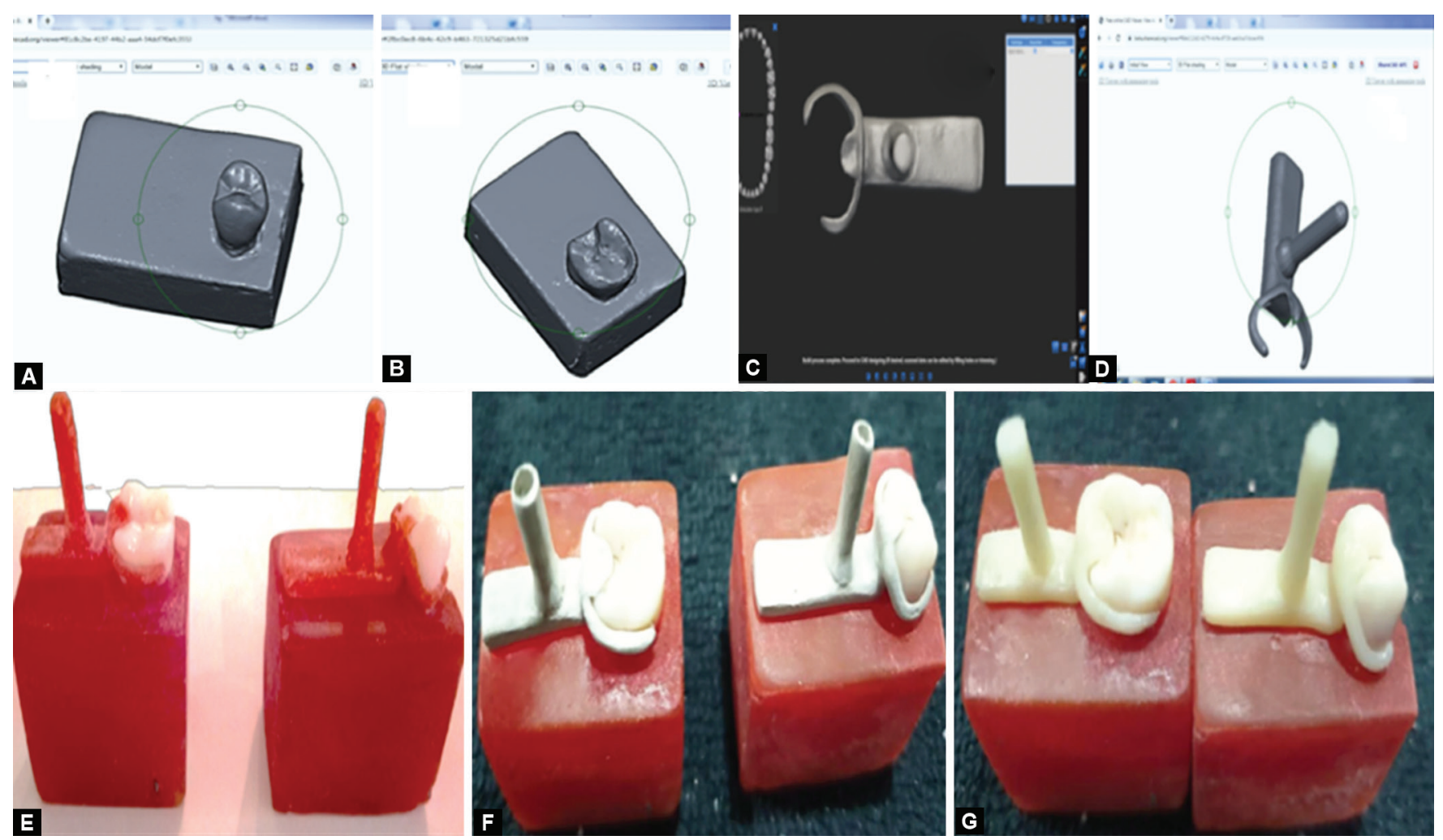

Figs 1 A to G: Steps for Aker clasp models manufacture for retention and deformation testing: (A and B) 3-D virtual images of the scanned test blocks with their natural teeth; (C and D) Final software design of the clasp assembly; (E) 3-D printed resin pattern for clasps secured on test blocks; (F) Finished acetal clasps; (G) Finished PEEK clasps all on the test blocks

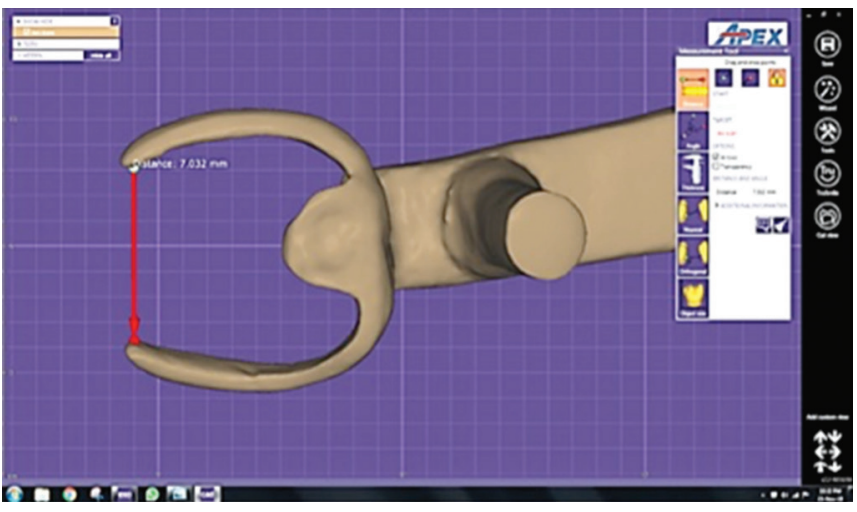

Fig. 2: Deformation of Aker clasp through measuring the distance between tips of the retentive and reciprocal arms using software micrometer

\section{Clasps Retention and Deformation Testing}

For clasp deformation, the software micrometer was used for measuring the distance between the tips of the retentive and reciprocal arms of the clasps using digital reference points, before and after aging (Fig. 2). For clasp retention, models were mounted on a universal testing machine (Lloyd Instruments Ltd). Each clasp was subjected to withdrawal force for three times using the attached cylindrical pin. Average value of the three times was taken as the retentive force of this clasp. Each clasp retentive forces were evaluated before and after total numbers of thermocycles at neutral pH (7.2) artificial saliva (Fig. 3). Specimens were tested at

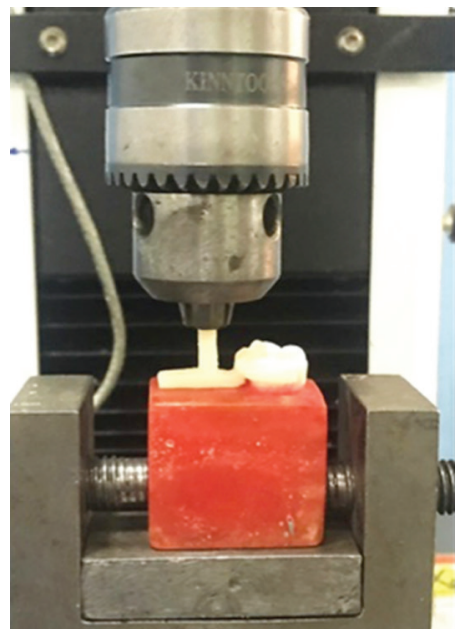

Fig. 3: Retention force testing through the attached cylindrical pin to Aker clasp using Lloyd tensile testing machine

room temperature with crosshead speed of $0.5 \mathrm{~mm} /$ minute and retentive forces were recorded in Newton $(\mathrm{N})$ before and after aging.

The sample size calculation was done using the $G^{*}$ power analysis (v3.1.9.2, University of Dusseldorf) software. It was calculated at: effect size $f=0.403$ and 1.76 , for mechanical and clasp tests, respectively), a error probability 0.05 , power of probability $80 \%$, and degree of freedom ( $\mathrm{df}$ ) $=6$. Data of flexural strength and surface microhardness tests were analyzed by two-way ANOVA with subsequent multicomparison testing by the post hoc Tukey's test. The Student's $t$-test and paired $t$-tests were used to statistically 
analyze clasps deformation and retention before and after aging. The statistical analysis was done using SPSS 16.0 (SPSS, Chicago, IL, USA) for Windows.

\section{Results}

Poly-ether-ether ketone showed the statistically significant highest mean values ( $p$ value $<0.05$ ) of both flexural strength (MPa) and VHN $\left(\mathrm{kg} / \mathrm{mm}^{2}\right)$ among all tested groups before and after aging (Tables 1 and 2, respectively). The statistical difference of the $\mathrm{pH}$ values of artificial saliva was significant ( $p$ value $<0.05$ ) on flexural strength and $\mathrm{VHN}$ of tested materials. The statistical difference of acetal was insignificant in $\mathrm{VHN}$ in acidic and alkaline $\mathrm{pH}(15.02 \pm$ 2.15 and $17.13 \pm 1.05 \mathrm{~kg} / \mathrm{mm}^{2}$, respectively), while PEEK showed statistically significant $\mathrm{HVN}$ in all tested $\mathrm{pH}$ values. The statistical difference between both materials was a significant decrease ( $p$ value $<0.05$ ) in terms of flexural strength for the various $\mathrm{pH}$ values after thermocycling.

Acetal clasps showed a statistically significant decrease ( $p$ value $<0.05$ ) in mean retentive forces $(\mathrm{N})$ after aging for both premolar and molar cases. On the other hand, PEEK retentive forces were not statistically significant ( $p$ value $>0.05$ ) in former cases (Table 3 ). Acetal clasps, for both molar and premolar, showed a statistically significant ( $p$ value $<0.05$ ) increase within the distance $(\mathrm{mm})$ between retentive and reciprocal arms after aging. In contrast, the statistical difference of PEEK clasps was insignificant ( $p$ value $>0.05$ ) in the former cases (Table 4).

\section{Discussion}

The oral environment is much complex than the model created in the current study and more difficult to be totally generated in an in vitro study. Nonetheless, the current aging model tried to approximate such complexity through combining thermal cycling dynamic stresses with the effect of the chemical composition of artificial saliva corresponding to different $\mathrm{pH}$ values. Thermal cycling was done within a $5-55^{\circ} \mathrm{C}$ range. This was reported as the temperature range of variable diet components, such as cold drinks, hot soup, or beverages. ${ }^{22}$ The number of thermal cycles was 2,000 . This number could be considered equivalent to less than a period of 6 months $\mathrm{s}^{23}$ or to less than months according to previous study ${ }^{24}$ that considered 10,000 cycles are equivalent to 1 year in clinical condition. The effect of these 2,000 cycles may exceed the formerly reported periods in the clinical practice when used within salivary $\mathrm{pH}$. The later may act as a catalyst to accelerate the thermal aging rate process. ${ }^{20}$ Furthermore, the dwell time of thermocycling was increased to 3 minutes, which is higher than the maximum reported time for 2 minutes. ${ }^{25}$ Extra dwell time allowed temperature conduction between artificial saliva within the plastic wrap and the surrounding water bath.

The null hypothesis had two assumptions; the first assumption was totally rejected. Both tested mechanical properties of all resins were significantly affected by combined aging, while the second one was partially rejected. Acetal clasps retention and deformations were remarkably reduced after aging, while PEEK clasps properties were not. Two famous TMs were used: aectal or POM copolymer and modified PEEK known as a high-performance polymer (BioHPP, Bredent $\mathrm{GmbH}$ ). The later contains $20 \%$ ceramic fillers and is considered a high-performance polymer. It has a white esthetic for removable partial dentures (RPDs) frameworks with better color appearance than conventional cobalt-chromium (Co-Cr). ${ }^{26,27}$ In the same way, POM is used for esthetic clasps construction since $1986 .^{28}$ This polymer is known for its resistance to wear ${ }^{27}$ and water sorption, ${ }^{29}$ especially in copolymer type. Furthermore, it is considered a suitable framework/clasp material for RPDs in allergic patients to Co-Cr frameworks. ${ }^{30}$

The results revealed that the acidic $\mathrm{pH}$ of artificial saliva had the most prominent effect on the tested resin mechanical properties, followed by alkaline $\mathrm{pH}$ after thermal cycles. The advantages of TMs included long-term stability of color and resistance to deformation and wear. ${ }^{31}$ Nevertheless, the mechanical properties of denture resins had significantly deteriorated when assessed in a wet environment than a dry one. ${ }^{29}$ This agrees with the findings of the present study and indicates the deteriorating effect caused by salivary biodegradation of the materials. ${ }^{32}$ This could be attributed to the chemical nature of both tested TMs. According to the classification of $\mathrm{pH}$-responsive materials, aectal and ketal (i.e., the term used for structures associated with ketones, e.g., PEEK) have chemical linkages that degrade due to $\mathrm{pH}$ variations. They are known to be

Table 1: Means and standard deviations (SD) of flexural strength (MPa) for all tested resins before and after thermocycling at different $\mathrm{pH}$ values

\begin{tabular}{lllll}
\hline & Control & $p H 5.8$ & $p H 7.2$ & $p H 8.3$ \\
\cline { 2 - 5 } Group & Mean $\pm S D$ & Mean $\pm S D$ & Mean $\pm S D$ & Mean $\pm S D$ \\
\hline Acetal resin & $88.35 \pm 4.41^{\mathrm{Ba}}$ & $67.39 \pm 3.93^{\mathrm{BC}}$ & $82.28 \pm 4.20^{\mathrm{Bab}}$ & $75.28 \pm 3.70^{\mathrm{Bb}}$ \\
Acrylic resin & $87.30 \pm 4.31^{\mathrm{Ba}}$ & $54.26 \pm 3.45^{\mathrm{Cc}}$ & $74.26 \pm 4.57^{\mathrm{Bb}}$ & $67.60 \pm 3.95^{\mathrm{Bb}}$ \\
PEEK resin & $204.94 \pm 9.15^{\mathrm{Aa}}$ & $160.76 \pm 6.45^{\mathrm{Ac}}$ & $173.35 \pm 6.15^{\mathrm{Acb}}$ & $177.94 \pm 9.55^{\mathrm{Ab}}$ \\
$p$ Value & $<0.001$ & $<0.001$ & $<0.001$ & $<0.001$ \\
\hline
\end{tabular}

All letters are for the Tukey's post hoc test. Means with same lowercase superscript letter (a-c) in each row are not significantly different at $p$ value $<0.05$. Means with same uppercase superscript letter (A-C) in each column are not significantly different at $p$ value $<0.05$

Table 2: Means and SD of VHN (kg/mm²) for all tested resins before and after thermocyling at different $\mathrm{pH}$ values

\begin{tabular}{llllr}
\hline & Control & $p H 5.8$ & $p H 7.2$ & $p H 8.3$ \\
\cline { 2 - 5 } Group & Mean $\pm S D$ & Mean $\pm S D$ & Mean $\pm S D$ & Mean $\pm S D$ \\
\hline Acetal resin & $20.84 \pm 2.50^{\mathrm{Ba}}$ & $15.02 \pm 2.15^{\mathrm{Cb}}$ & $18.27 \pm 1.38^{\mathrm{Bab}}$ & $17.13 \pm 1.05^{\mathrm{Bb}}$ \\
Acrylic resin & $16.73 \pm 0.81^{\mathrm{Ca}}$ & $11.30 \pm 1.04^{\mathrm{BC}}$ & $15.11 \pm 0.51^{\mathrm{Cb}}$ & $14.32 \pm 0.90^{\mathrm{Cb}}$ \\
PEEK resin & $24.51 \pm 0.90^{\mathrm{Aa}}$ & $19.36 \pm 0.45^{\mathrm{Ac}}$ & $23.25 \pm 0.93^{\mathrm{Aab}}$ & $21.92 \pm 1.42^{\mathrm{Ab}}$ \\
$p$ Value & 0.003 & 0.003 & $<0.001$ & $<0.001$ \\
\hline
\end{tabular}

All letters are for the Tukey's post hoc test. Means with the same lowercase superscript letter (a-c) in each row are not significantly different at $p$ value $<$ 0.05. Means with the same uppercase superscript letter $(\mathrm{A}-\mathrm{C})$ in each column are not significantly different at $p$ value $<0.05$ 
Table 3: Retentive force values $(N)$ of acetal and PEEK clasps before and after thermocycling at neutral $\mathrm{pH}$ artificial saliva

\begin{tabular}{llll}
\hline & & $\begin{array}{l}\text { Molar } \\
(\text { mean } \pm S D)\end{array}$ & $\begin{array}{l}\text { Premolar } \\
(\text { mean } \pm S D)\end{array}$ \\
\hline Acetal resin & Before & $21.12 \pm 1.70$ & $25.20 \pm 1.40$ \\
& After & $16.63 \pm 0.60$ & $17.00 \pm 0.70$ \\
& Paired $t$-test & $0.027^{*}$ & $0.008^{*}$ \\
PEEK resin & Before & $26.53 \pm 0.90$ & $29.23 \pm 2.20$ \\
& After & $24.66 \pm 1.20$ & $28.70 \pm 2.00$ \\
& Paired $t$-test & 0.081 & 0.067 \\
\hline
\end{tabular}

*Means statistically significant at $p$ value $<0.05$

Table 4: Mean values and SD of distances $(\mathrm{mm})$ between clasp tips before and after thermocycling at neutral $\mathrm{pH}$ artificial saliva

\begin{tabular}{llll}
\hline & & $\begin{array}{l}\text { Molar } \\
(\text { mean } \pm S D)\end{array}$ & $\begin{array}{l}\text { Premolar } \\
(\text { mean } \pm S D)\end{array}$ \\
\hline Acetal resin & Before & $7.56 \pm 0.02$ & $6.82 \pm 0.07$ \\
& After & $7.68 \pm 0.02$ & $7.13 \pm 0.10$ \\
& Paired $t$-test & $0.040^{*}$ & $0.050^{*}$ \\
PEEK resin & Before & $7.64 \pm 0.05$ & $6.22 \pm 0.05$ \\
& After & $7.71 \pm 0.07$ & $7.16 \pm 0.02$ \\
& Paired $t$-test & 0.140 & 0.070 \\
\hline
\end{tabular}

*Means statistically significant at $p$ value $<0.05$

moderately stable under alkaline conditions but readily hydrolyze to the corresponding carbonyl compound (aldehyde and ketone) and alcohol under acidic conditions. ${ }^{33}$ Furthermore, it was reported that low $\mathrm{pH}$ aging could increase the erosive effect on polymers. ${ }^{20}$ The less prominent, but still statistically significant, the influence of the alkaline medium on the tested mechanical properties may be attributed to the interaction caused by $\mathrm{OH}$ ions during the hydrolysis process. In fact, alkaline $\mathrm{pH}$ can produce millions of hydroxyl ions that are much higher than such ions in saliva with neutral pH consequently increases the likelihood of breaking polymer ties. ${ }^{34}$

Our results revealed the highest flexural strength and $\mathrm{VHN}$ for PEEK before and after combined thermal and $\mathrm{pH}$ aging. On the other hand, the PMMA polymer showed the least properties in both former cases. This might be attributed to differences between tested resins within their polymer chemistry, degree of crosslinking, presence of another inorganic phase, and the ability to resist fluid sorption. Poly-ether-ether ketone used in the present study has a microstructure based on being a highly cross-linked polymer. ${ }^{35}$ Moreover, it contains 20\% ceramic filler (with a grain size of $0.3-0.5$ $\mu \mathrm{m})$. The fine size of ceramic fillers enables them to penetrate and plug the space between the chains of the PEEK polymer and as a result, it restricts the mobility of chains and reduces the penetration of different aging solutions. ${ }^{19}$ The previous composition of PEEK could provide its priority of higher strength properties among tested resins. Furthermore, the presence of inorganic filler in addition to the semicrystallinity nature $(30-35 \% \text { crystalline })^{36,37}$ could improve the rigidity of PEEK over acetal, which lacks the ceramic filler inorganic phase. This may justify why retentive forces of PEEK clasps are higher than less rigid acetal resin. Our findings go hand in hand with Tannous et al., ${ }^{13}$ who found that PEEK had retentive forces than acetal in both used undercuts $(0.25$ and 0.5 $\mathrm{mm}$ ) when both clasps have the same design and dimensions.

The composite structure of PEEK had significantly deteriorated after combined aging procedures of the current study. These results agree with previous results reporting significant deterioration of composite PEEK structure elastic modulus and nanohardness after 30 days of aging in different three $\mathrm{pH}$ values. ${ }^{17,38}$ The general mechanical performance of a heat-cured polymer composite, like the current PEEK structure, is not only evaluated by the properties of its phases but also with intensity and the durability of the interfacial area between the two phases structure. ${ }^{39}$ Fluid absorption at the interfacial areas is aggravated by the presence of any damaged bonding areas or defects. The absorbed fluid particles can cause plasticization of the resin phase and embrittlement of the macromolecular skeleton by hydrolysis and osmotic cracking. ${ }^{40}$

The tested acetal clasps showed a significant increase in the distance between two clasp tips (i.e., deformation). This agrees with previous work where acetal clasps with higher flexibility showed higher deformation than high rigidity $\mathrm{Co}-\mathrm{Cr}$ clasps after fatigue aging. ${ }^{41}$ Polymethyl methacrylate showed the least mechanical properties among all tested resins. It was reported that a storage period of 24 hours in water could worsen the mechanical properties of the PMMA matrix. That may be due to the significant swelling of PMMA in lateral and vertical directions ${ }^{42}$ indicating that the solvent molecules penetrate into the PMMA matrix and break the intermolecular bonding between polymer networks. The current study results may vary in the actual oral environment for its known complexity. Further studies are needed using the current combined thermal and $\mathrm{pH}$ wet aging for longer periods of cycles corresponding to longer clinical performance.

\section{ConCLUSION}

The PEEK polymer had the superior surface and strength mechanical properties in all groups than acetal polymers. Combined thermal cycling at different artificial saliva $\mathrm{pH}$ values deteriorates the mechanical properties of all tested resins. Polymethyl methacrylate clasps were superior, in retention and resistance to deformation to acetal clasps before and after combined thermal and neutral $\mathrm{pH}$ salivary aging.

\section{References}

1. Barclay CW, Spence D, Laird WRE. Intra-oral temperatures during function. J Oral Rehabil 2005;32(12):886-894. DOI: 10.1111/j.13652842.2005.01509.x.

2. Ernst CP, Canbek K, Euler T, et al. In vivo validation of the historical in vitro thermocycling temperature range for dental materials testing. Clin Oral Investig 2004;8(3):130-138. DOI: 10.1007/s00784-004-0267-2.

3. Minich DM, Bland JS. Acid-alkaline balance: role in chronic disease and detoxification. Altern Ther Health Med 2007;13(4):62-65.

4. Cavalcanti AN, Mitsui FHO, Ambrosano GMB, et al. Influence of adhesive systems and flowable composite lining on bond strength of class II restorations submitted to thermal and mechanical stresses. J Biomed Mater Res - Part B Appl Biomater 2007;80(1):52-58. DOI: 10.1002/jbm.b.30567.

5. Archadian N, Kawano F, Ohguri T, et al. Flexural strength of rebased denture polymers. J Oral Rehabil 2000;27(8):690-696. DOI: 10.1046/j.1365-2842.2000.00552.x.

6. Mazzitelli C, Monticelli F, Toledano M, et al. Effect of thermal cycling on the bond strength of self-adhesive cements to fiber posts. Clin Oral Investig 2012;16(3):909-915. DOI: 10.1007/s00784-011-0576-1.

7. Morresi AL, D'Amario M, Capogreco M, et al. Thermal cycling for restorative materials: does a standardized protocol exist in laboratory testing? A literature review. J Mech Behav Biomed Mater 2014;29:295308. DOI: 10.1016/j.jmbbm.2013.09.013.

8. Hristov I, Yankov S. Thermoplastic materials in the dental practice: a review. Int J Sci Res 2017;6:1074-1076. 
9. Nandal $S$, Ghalaut $P$, Shekhawat $H$, et al. New era in denture base resins: a review. Dent J Adv Stud 2013;01(03):136-143. DOI: 10.1055/s0038-1671969.

10. Arda T, Arikan A. An in vitro comparison of retentive force and deformation of acetal resin and cobalt-chromium clasps. J Prosthet Dent 2005;94(3):267-274. DOI: 10.1016/j.prosdent.2005.06.009.

11. De Torres EM, de Siqueira Damasceno II, do Amaral BA, et al. Effect of acetyl resin retentive arms on the retentive force of circumferential clasps: an in vitro study. J Prosthodont Res 2012;56(3):216-221. DOI: 10.1016/j.jpor.2011.09.003.

12. Muhsin SA, Wood DJ, Johnson A, et al. Effects of novel polyetheretherketone (PEEK) clasp design on retentive force at different tooth undercuts. JODR 2018;5:13-24.

13. Tannous F, Steiner M, Shahin R, et al. Retentive forces and fatigue resistance of thermoplastic resin clasps. Dent Mater 2012;28(3):273278. DOI: 10.1016/j.dental.2011.10.016.

14. Schwitalla AD, Spintig T, Kallage I, et al. Flexural behavior of PEEK materials for dental application. Dent Mater 2015;31(11):1377-1384. DOI: 10.1016/j.dental.2015.08.151.

15. Najeeb S, Zafar MS, Khurshid Z, et al. Applications of polyetheretherketone (PEEK) in oral implantology and prosthodontics. J Prosthodont Res 2016;60(1):12-19. DOI: 10.1016/j.jpor.2015.10.001.

16. Polychronakis N, Lagouvardos EP, Polyzois G, et al. Color changes of polyetheretherketone (PEEK) and polyoxymethelene (POM) denture resins on single and combined staining/cleansing action by $\mathrm{CIELab}$ and CIEDE2000 formulas. J Prosthodont Res 2019(2):6-13. DOI: 10.1016/j.jpor.2019.06.005.

17. Parlani S, Agarwal B, Malaiya A, et al. Evaluation of flexural modulus of flexible denture base material kept in water, denture cleanser, artificial saliva, and open air for different time intervals: an in vitro study. Int J Prosthodont Restor Dent 2018;8:54-58.

18. Nogueira SS, Ogle RE, Davis EL. Comparison of accuracy between compression- and injection-molded complete dentures. J Prosthet Dent 1999;82(3):291-300. DOI: 10.1016/s0022-3913(99)70083-1.

19. Assunção WG, Gomes ÉA, Barão VA, et al. Effect of storage in artificial saliva and thermal cycling on Knoop hardness of resin denture teeth. J Prosthodont Res 2010;54(3):123-127. DOI: 10.1016/j.jpor.2009.12.001.

20. Medeiros IS, Gomes MN, Loguercio AD, et al. Diametral tensile strength and Vickers hardness of a composite after storage in different solutions. J Oral Sci 2007;49(1):61-66. DOI: 10.2334/ josnusd.49.61.

21. Momoi Y, Hirosaki K, Kohno A, et al. Flexural properties of resinmodified "hybrid" glass-ionomers in comparison with conventional acid-base glass-ionomers. Dent Mater J 1995;14(2):109-19. DOI: 10.4012/dmj.14.109.

22. Budtz-Jorgensen E. Materials and methods for cleaning dentures. J Proth Dent 1979;42:619-623.

23. Stewardson DA, Shortall AC, Marquis PM. The effect of clinically relevant thermocycling on the flexural properties of endodontic post materials. J Dent 2010;38(5):437-442. DOI: 10.1016/j.jdent.2010. 02.003.

24. Gale MS, Darvell BW. Thermal cycling procedures for laboratory testing of dental restorations. J Dent 1999;27(2):89-99. DOI: 10.1016/ s0300-5712(98)00037-2.

25. Stavridakis MM, Kakaboura Al, Ardu S, et al. Marginal and internal adaptation of bulk-filled class I and cuspal coverage direct resin composite restorations. Oper Dent 2007;32(5):515-523. DOI: 10.2341/06-157.

26. Wimmer T, Huffmann AM, Eichberger M, et al. Two-body wear rate of PEEK, CAD/CAM resin composite and PMMA: effect of specimen geometries, antagonist materials and test set-up configuration. Dent Mater 2016;32(6):e127-e136. DOI: 10.1016/j.dental.2016.03.005.

27. Zok FW, Miserez A. Property maps for abrasion resistance of materials. Acta Mater 2007;55(18):6365-6371. DOI: 10.1016/j. actamat.2007.07.042.

28. Fitton JS, Davies EH, Howlett JA, et al. The physical properties of a polyacetal denture resin. Clin Mater 1994;17(3):125-129. DOI: 10.1016/0267-6605(94)90135-x.

29. Arikan A, Ozkan YK, Arda T, et al. An in vitro investigation of water sorption and solubility of two acetal denture base materials. Eur J Prosthodont Restor Dent 2005;13(3):119-122.

30. Lekha K, Savitha N, Roseline M, et al. Acetal resin as an esthetic clasp material. J Interdiscip Dent 2012;2:11.

31. Ardelean L, Bortun CM, Podariu AC, et al. Manufacture of different types of thermoplastic. Thermoplast - Compos Mater 2012; 25-48.

32. Rusu LC, Ardelean L. CAD/CAM technology concerning biocompatibilty in zirconia all-ceramic restoration. Rev Chim (Bucharest) 2012;63:513-515.

33. Liu B, Thayumanavan $\mathrm{S}$. Substituent effects on the $\mathrm{pH}$ sensitivity of acetals and ketals and their correlation with encapsulation stability in polymeric nanogels. J Am Chem Soc 2017;139(6):2306-2317. DOI: 10.1021/jacs.6b11181.

34. Bagheri R, Tyas MJ, Burrow MF. Subsurface degradation of resinbased composites. Dent Mater 2007;23(8):944-951. DOI: 10.1016/j. dental.2006.06.035.

35. Katsikis N, Zahradnik F, Helmschrott A, et al. Thermal stability of poly(methyl methacrylate)/silica nano- and microcomposites as investigated by dynamic-mechanical experiments. Polym Degrad Stab 2007;92(11):1966-1976. DOI: 10.1016/j.polymdegradstab.2007.08.009.

36. Jaekel DJ, MacDonald DW, Kurtz SM. Characterization of PEEK biomaterials using the small punch test. J Mech Behav Biomed Mater 2011;4(7):1275-1282. DOI: 10.1016/j.jmbbm.2011.04.014.

37. Kurtz SM, Devine JN. PEEK biomaterials in trauma, orthopedic, and spinal implants. Biomaterials 2007;28(32):4845-4869. DOI: 10.1016/j. biomaterials.2007.07.013.

38. Gao S, Gao S, Xu B, et al. Effects of different pH-values on the nanomechanical surface properties of PEEK and CFR-PEEK compared to dental resin-based materials. Materials (Basel) 2015;8(8):4751-4767.

39. Ray BC. Temperature effect during humid ageing on interfaces of glass and carbon fibers reinforced epoxy composites. J Colloid Interface Sci 2006;298(1):111-117. DOI: 10.1016/j.jcis.2005.12.023.

40. Sethi S, Ray BC. Environmental effects on fibre reinforced polymeric composites: evolving reasons and remarks on interfacial strength and stability. Adv Colloid Interface Sci 2015;217:43-67. DOI: 10.1016/j. cis.2014.12.005.

41. Wu JC, Latta Jr GH, Wicks RA, et al. In vitro deformation of acetyl resin and metal alloy removable partial denture direct retainers. J Prosthet Dent 2003;90(6):586-590. DOI: 10.1016/j.prosdent.2003.09.020.

42. N'Diaye M, Pascaretti-Grizon F, Massin P, et al. Water absorption of poly(methyl methacrylate) measured by vertical interference microscopy. Langmuir 2012;28(31):11609-11614. DOI: 10.1021/ la302260a. 